\title{
The Impact of Middle Turbinate Concha Bullosa on the Severity of Inferior Turbinate Hypertrophy in Patients with a Deviated Nasal Septum
}

\author{
(D) C.M. Tomblinson, (D) M.-R. Cheng, (DD. Lal, and (D).M. Hoxworth
}

\begin{abstract}
BACKGROUND AND PURPOSE: Inferior turbinate hypertrophy and concha bullosa often occur opposite the direction of nasal septal deviation. The objective of this retrospective study was to determine whether a concha bullosa impacts inferior turbinate hypertrophy in patients who have nasal septal deviation.
\end{abstract}

MATERIALS AND METHODS: The electronic medical record was used to identify sinus CT scans exhibiting nasal septal deviation for 100 adult subjects without and 100 subjects with unilateral middle turbinate concha bullosa. Exclusion criteria included previous sinonasal surgery, tumor, sinusitis, septal perforation, and craniofacial trauma. Nasal septal deviation was characterized in the coronal plane by distance from the midline (severity) and height from the nasal floor. Measurement differences between sides for inferior turbinate width (overall and bone), medial mucosa, and distance to the lateral nasal wall were calculated as inferior turbinate hypertrophy indicators.

RESULTS: The cohorts with and without concha bullosa were similarly matched for age, sex, and nasal septal deviation severity, though nasal septal deviation height was greater in the cohort with concha bullosa than in the cohort without concha bullosa (19.1 $\pm 4.3 \mathrm{~mm}$ versus $13.5 \pm 4.1 \mathrm{~mm}, P<.001)$. Compensatory inferior turbinate hypertrophy was significantly greater in the cohort without concha bullosa than in the cohort with it as measured by side-to-side differences in turbinate overall width, bone width, and distance to the lateral nasal wall $(P<.01)$, but not the medial mucosa. Multiple linear regression analyses found nasal septal deviation severity and height to be significant predictors of inferior turbinate hypertrophy with positive and negative relationships, respectively $(P<.001)$.

CONCLUSIONS: Inferior turbinate hypertrophy is directly proportional to nasal septal deviation severity and inversely proportional to nasal septal deviation height. The effect of a concha bullosa on inferior turbinate hypertrophy is primarily mediated through influence on septal morphology, because the nasal septal deviation apex tends to be positioned more superior from the nasal floor in these patients.

ABBREVIATIONS: $\mathrm{CB}+=$ cohort with concha bullosa; $\mathrm{CB}-=$ cohort without concha bullosa; $\mathrm{ITH}=$ inferior turbinate hypertrophy; $\mathrm{NSD}=$ nasal septal deviation; $\Delta=$ side-to-side difference in inferior turbinate measurements

$\mathbf{N}$ asal airway obstruction is a challenging problem that can arise from multiple etiologies, which include structural abnormalities such as nasal septal deformity and turbinate hypertrophy. Inferior turbinate hypertrophy (ITH) has received much attention in the literature in the debate over optimal surgical management of nasal obstruction. ${ }^{1}$ Although the term "hypertrophy" is most accurately reserved for the overall enlargement of an organ because of increasing cell size, its use is widely accepted in the setting of turbinate enlargement secondary to greater thick-

Received September 25, 2015; accepted after revision December 21.

From the Departments of Radiology (C.M.T., J.M.H.), Biostatistics (M.-R.C.), and Otolaryngology (D.L.), Mayo Clinic, Phoenix, Arizona.

Paper presented in preliminary form at: Annual Meeting of the American Society Head and Neck Radiology, September 10-14, 2014; Seattle, Washington.

Please address correspondence to Joseph M. Hoxworth, MD, 5777 E Mayo Blvd, Phoenix, AZ 85054; e-mail: hoxworth.joseph@mayo.edu

http://dx.doi.org/10.3174/ajnr.A4705 ness of soft-tissue and/or bone components. ${ }^{2-5}$ Although limited normative data has been published on inferior turbinate size by using CT, ITH remains a clinical diagnosis. ${ }^{6}$

ITH has been commonly described as occurring contralateral to the direction of nasal septal deviation (NSD) or, alternatively phrased, along the concave side of the septum..$^{2,3,7-14}$ Because of this association, it has been speculated that ITH is compensatory, to create physiologically favorable nasal airflow turbulence and to protect the mucosa from excessive drying and crusting with increased air flow. In other words, the inferior turbinate may have progressively enlarged to fill the void in the nasal cavity created by the shifted midline with the undesirable result of a smaller-than-expected crosssectional area for air passage. ${ }^{2}$ Using septoplasty to correct NSD without addressing the ITH may have the unintended consequence of worsening symptomatic nasal obstruction. ${ }^{7}$

Concha bullosa is an anatomic variant of ethmoid air cell development in which pneumatization most commonly extends 
into the middle turbinate. This can be limited to the vertical lamella, extend into the bulbous portion, or extensively involve the vertical lamella and bulbous segment of the middle turbinate. ${ }^{15}$ If one allowed some outlier data, the prevalence is likely in the range of $21 \%-53 \% .{ }^{15-27}$ Some of the reported variability can be attributed to differences in the populations being evaluated, the type of evaluation (ie, CT versus surgery), and the definition of concha bullosa (ie, whether to include small lamellar types). Similar to ITH, a preponderance of published reports support a strong association between the presence of concha bullosa and NSD, in which the nasal septum typically bows toward the contralateral side and may increasingly do so when middle turbinate pneumatization is greatest. ${ }^{23,24,27-30}$ Moreover, in bilateral cases, the nasal septum is usually near midline when the conchae bullosa are balanced in size but usually deviates away from an asymmetrically enlarged dominant concha bullosa.

When one controls for the shape and severity of a deviated nasal septum, it has yet to be determined whether a concha bullosa significantly influences the presence of ipsilateral ITH. Logically, an interaction may exist between the structures because the concha bullosa and ITH both commonly develop along the concave side of a deviated nasal septum within a secondarily widened nasal cavity. The objective of this study was to assess patients with NSD on CT in an attempt to identify whether the presence or absence of a concha bullosa influences ipsilateral ITH.

\section{MATERIALS AND METHODS}

This retrospective study, which is compliant with the Health Insurance Portability and Accountability Act, was approved by the institutional review board at the authors' institution, and the need for informed consent was waived. The radiology information management system was used to identify patients who underwent noncontrast sinus CT between January 1, 2011, and July 1, 2014. All sinus CT scans were acquired with a 64-detector scanner (LightSpeed VCT or Discovery CT750 HD; GE Healthcare, Milwaukee, Wisconsin), and the same CT protocol was used for all studies (120 kV[peak], $180 \mathrm{~mA}, 0.5$-second rotation time, 0.531 pitch, and $0.625-\mathrm{mm}$ section collimation). No topical intranasal vasoconstrictors were administered at the time of imaging.

The sinus CT scans and corresponding electronic medical records were evaluated in consecutive reverse-chronologic fashion to determine study eligibility. We specifically excluded patients with a Lund-Mackay score greater than zero, prior sinonasal surgery, CT or clinical findings of sinonasal polyposis, a history of head and neck tumor or irradiation, nasal septal perforation, and a documented history of craniofacial trauma. Inclusion required that patients were at least 18 years of age at the time of imaging and that the sinus CT was of diagnostic quality. Additionally, all patients were required to have unilateral NSD without a minimum threshold for severity. Subjects with S-shaped or other complex bidirectional nasal septal deformities were excluded. In total, we enrolled 200 patients with NSD: 100 with a unilateral middle turbinate concha bullosa $(\mathrm{CB}+)$ and 100 without a concha bullosa $(\mathrm{CB}-)$. As previously published, concha bullosa was defined as $>50 \%$ pneumatization of the vertical height of the middle turbinate, thereby excluding very small conchae bullosa or pneumatization of the vertical lamella only. ${ }^{24}$

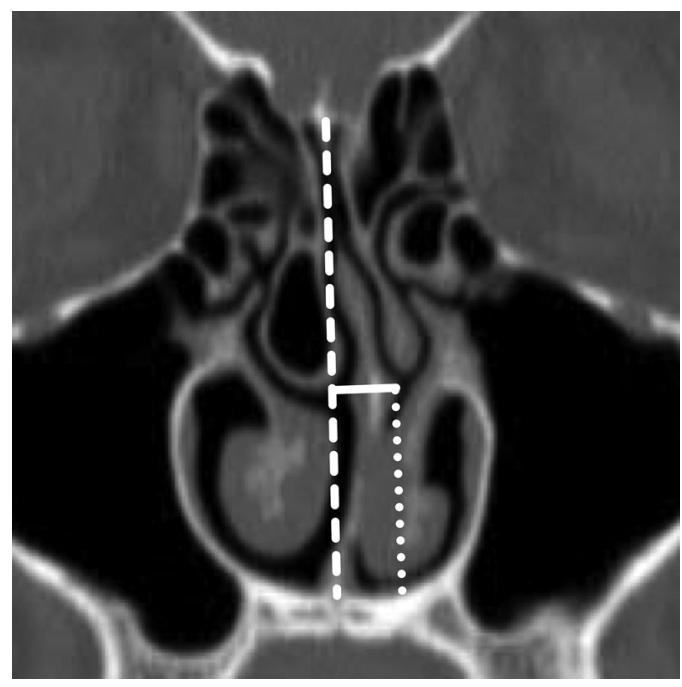

FIG 1. Coronal reformatted image from noncontrast sinus CT demonstrates the measurements of NSD. The midline is defined by a dashed line extending from the crista galli to the nasal crest. NSD severity (solid line) is measured to the point of maximal NSD orthogonal to the midline. NSD height is determined by measuring the distance from the point of maximal NSD to the floor of the nasal cavity parallel to the midline (dotted line).

Image assessment was performed by a board-certified neuroradiologist by using a PACS. The following measurements were performed on $1.25-\mathrm{mm}$ coronal reformations that were rendered in a bone algorithm and viewed at window level and width of 450 $\mathrm{HU}$ and $2500 \mathrm{HU}$, respectively:

Concha Bullosa. The maximum transverse width and craniocaudal length of the middle turbinate concha bullosa $(\mathrm{CB}+$ group only).

NSD. Using the image on which the NSD was most severe, we drew a line from the crista galli to the nasal crest to define the midline. An orthogonal measurement was taken from the midline to the apex of maximal nasal septal deviation (NSD severity). The vertical distance from the apex to the floor of the nasal cavity was measured parallel to midline (NSD height), and the direction of septal deviation was recorded (Fig 1).

Inferior Turbinate. Because no standard definition exists for ITH on CT, 4 measurements were acquired to document the width of the inferior turbinate and the degree to which it projected into the nasal cavity.

1) Lateral offset (Fig 2A) represents the maximum transverse distance from the most medial aspect of the inferior turbinate bone to the lateral nasal wall.

2) Width (Fig $2 A$ ) was determined by the maximum transverse width of the pendulous portion of the inferior turbinate inclusive of soft tissue and bone.

3) Bone width (Fig 2B) represents the maximum transverse width of the inferior turbinate bone.

4) Medial mucosa width (Fig $2 B$ ) was a transverse measurement at the point of maximal soft-tissue thickness along the medial aspect of the inferior turbinate.

For consistency, these measurements were all performed by the same neuroradiologist at the level of the ostiomeatal complex

AJNR Am J Neuroradiol 37:1324-30 Jul 2016 www.ajnr.org

1325 

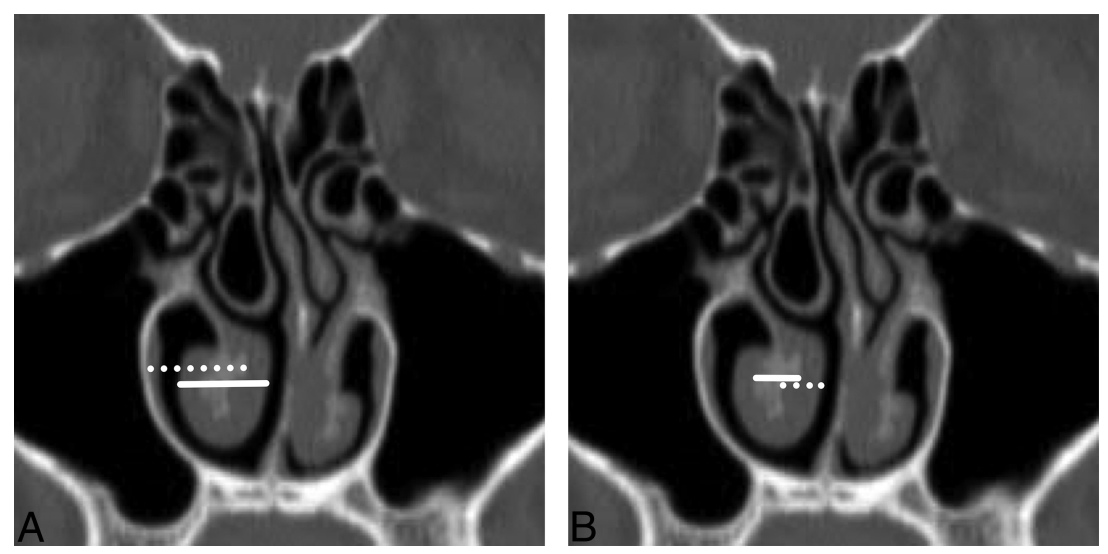

FIG 2. Coronal reformatted image from noncontrast sinus CT demonstrates the measurements of inferior turbinate size. A, The maximum transverse distance from the most medial aspect of the inferior turbinate conchal bone to the lateral nasal wall (lateral offset) is defined by the dotted line. The maximum transverse width of the pendulous portion of the inferior turbinate inclusive of soft tissue and bone (width) is depicted by the solid line. $B$, The greatest width of the inferior turbinate bone (bone width) is demarcated with a solid line, while the thickest transverse dimension of the soft tissue along the medial aspect of the inferior turbinate (medial mucosa width) is identified with a dotted line.

Table 1: Comparison between CB groups for patient characteristics and measurements ${ }^{\mathrm{a}}$

\begin{tabular}{lcccc}
\multicolumn{1}{c}{ Variable } & $\begin{array}{c}\text { CB- } \\
(\boldsymbol{n}=100)\end{array}$ & $\begin{array}{c}\text { CB+ } \\
(\boldsymbol{n}=100)\end{array}$ & $\begin{array}{c}\text { Entire Cohort } \\
(\boldsymbol{N}=200)\end{array}$ & $\boldsymbol{P}$ Value \\
\hline Age (yr) & $52.6(16.6)$ & $54.2(17.4)$ & $53.4(17.0)$ & $.50^{\mathrm{b}}$ \\
Sex (female) & $54(54.0 \%)$ & $59(59.0 \%)$ & $113(56.5 \%)$ & $.48^{\mathrm{C}}$ \\
NSD severity (mm) & $7.1(1.6)$ & $7.3(2.0)$ & $7.2(1.8)$ & $.25^{\mathrm{b}}$ \\
NSD height (mm) & $13.5(4.1)$ & $19.1(4.3)$ & $16.3(5.1)$ & $<.001^{\mathrm{b}}$ \\
$\Delta$ Lateral offset (mm) & $2.7(1.8)$ & $1.9(2.0)$ & $2.3(1.9)$ & $<.01^{\mathrm{b}}$ \\
$\Delta$ Width (mm) & $3.4(2.0)$ & $2.5(2.3)$ & $2.9(2.2)$ & $<.01^{\mathrm{b}}$ \\
$\Delta$ Bone width (mm) & $1.3(0.7)$ & $0.9(0.8)$ & $1.1(0.8)$ & $<.01^{\mathrm{b}}$ \\
$\Delta$ Medial mucosa width (mm) & $1.0(1.5)$ & $0.7(1.5)$ & $0.8(1.5)$ & $.13^{\mathrm{b}}$ \\
\hline
\end{tabular}

${ }^{a}$ All values are displayed as mean (SD) except for sex, which is presented as count (\%).

${ }^{\mathrm{b}}$ Two-sample $t$ test was used to compare the $\mathrm{CB}+$ and $\mathrm{CB}-$ groups.

${ }^{c} \chi^{2}$ tests were used to compare the $\mathrm{CB}+$ and $\mathrm{CB}-$ groups.

on the posterior-most coronal image on which the primary maxillary sinus ostium was visible. As an indicator of ITH for each patient, side-to-side differences $(\Delta)$ in inferior turbinate measurements were calculated by subtracting the side ipsilateral to the apex of the NSD from the contralateral side. In other words, a positive value for this difference would support the hypothesis that the inferior turbinate on the concave side of the nasal septum was larger than the one on the opposite side.

To assess the potentially confounding influence of vasocongestion related to the normal nasal cycle, we recorded the maximal mucosal thickness along the inferior aspect of the middle turbinate for the concave and convex sides of the deviated nasal septum.

Patient characteristics and side-to-side differences for the inferior turbinate measurements were compared between the presence and absence of the concha bullosa by using the 2-sample $t$ test for continuous variables and the $\chi^{2}$ test for categoric variables. Pearson correlation coefficients were also used to assess the strength and direction of linear relationships for the inferior turbinate measurement differences relative to NSD severity and NSD height for all 200 subjects, in addition to being stratified by CB+ and $\mathrm{CB}$ - groups. Multiple linear regression models were conducted for predicting the side-to-side differences in inferior turbinate measurements, controlling for $\mathrm{CB}+$, NSD severity, NSD height, and potential interaction terms. A paired $t$ test was used to compare the middle turbinate mucosa thickness on the concave side of the deviated nasal septum with that on the convex side. Potential correlations between the concha bullosa width, concha bullosa length, NSD severity, and NSD height were examined by using Pearson correlation coefficients, and simple linear regressions were used for modeling the relationships. All analyses were performed with SAS 9.4 (SAS Institute, Cary, North Carolina). All hypothesis tests were 2 -sided, and statistical significance was defined as $P<.05$.

\section{RESULTS}

The $\mathrm{CB}+$ and $\mathrm{CB}-$ cohorts were similarly matched in age, sex, and NSD severity (Table 1 ). The mean (SD) transverse width and craniocaudal length of the middle turbinate conchae bullosa were $7.5 \mathrm{~mm}(2.2 \mathrm{~mm})$ and $15.5 \mathrm{~mm}$ $(3.8 \mathrm{~mm})$, respectively, in the $\mathrm{CB}+$ group, and the NSD height was significantly greater in the presence of a contralateral middle turbinate concha bullosa (mean, $19.1 \pm 4.3 \mathrm{~mm}$ versus $13.5 \pm 4.1 \mathrm{~mm} ; P<.001)$. Concha bullosa width showed statistically significant moderate correlations for NSD height (Pearson $r=0.30, P<.01$ ) and NSD severity (Pearson $r=0.20, P=$ $.04)$. However, concha bullosa height was not significantly correlated with NSD height or NSD severity. Because concha bullosa height and width were highly correlated (Pearson $r=0.53, P<.001$ ), simple linear regression was performed by using only concha bullosa width as the predictor. There were statistically significant positive relationships between NSD height and concha bullosa width ( $\beta$ coefficient $=0.61$, standard error $=0.20, P<.01)$ and NSD severity and concha bullosa width $(\beta$ coefficient $=0.19$, standard error $=$ 0.09, $P<.04)$.

Bivariate analysis was initially undertaken to evaluate the indicators of ITH related to concha bullosa status. No significant relationships were identified on the basis of age or sex. As seen in Table 1, the values for $\Delta$ lateral offset, $\Delta$ width, and $\Delta$ bone width were greater in the $\mathrm{CB}-$ group compared with $\mathrm{CB}+$, but the results for $\Delta$ medial mucosa width did not reach significance. However, this comparison does not correct for the potentially confounding influence of NSD severity and NSD height. Pearson correlation coefficients were examined to determine the strength and direction of potential relationships between the side-to-side differences in inferior turbinate measurements and NSD severity and NSD height (Table 2). When we evaluated the data in aggregate and divided into $\mathrm{CB}+$ and $\mathrm{CB}-$ groups, $\Delta$ lateral offset, $\Delta$ width, and $\Delta$ bone width showed strong potential as indicators of ITH as correlated to NSD severity and NSD height, while the level of strength for $\Delta$ medial mucosa width was again not as strong. 
Table 2: Pearson correlation coefficients ( $P$ value) between side-to-side differences in inferior turbinate measurements and risk factors by concha bullosa group

\begin{tabular}{|c|c|c|c|c|c|c|}
\hline \multirow[b]{2}{*}{ Variable } & \multicolumn{2}{|c|}{ CB- $(n=100)$} & \multicolumn{2}{|c|}{$C B+(n=100)$} & \multicolumn{2}{|c|}{ Entire Cohort $(N=200)$} \\
\hline & $\begin{array}{l}\text { Septal } \\
\text { Deviation } \\
\text { Severity }\end{array}$ & $\begin{array}{l}\text { Septal } \\
\text { Deviation } \\
\text { Height }\end{array}$ & $\begin{array}{l}\text { Septal } \\
\text { Deviation } \\
\text { Severity }\end{array}$ & $\begin{array}{l}\text { Septal } \\
\text { Deviation } \\
\text { Height }\end{array}$ & $\begin{array}{c}\text { Septal } \\
\text { Deviation } \\
\text { Severity }\end{array}$ & $\begin{array}{l}\text { Septal } \\
\text { Deviation } \\
\text { Height }\end{array}$ \\
\hline$\Delta$ Lateral offset & $0.31^{\mathrm{a}}(<.01)$ & $-0.13(.20)$ & $0.36^{\mathrm{a}}(<.001)$ & $-0.17(.10)$ & $0.31^{\mathrm{a}}(<.001)$ & $-0.24^{\mathrm{a}}(<.001)$ \\
\hline$\Delta$ Width & $0.23^{a}(.02)$ & $-0.22^{\mathrm{a}}(.03)$ & $0.23^{\mathrm{a}}(.02)$ & $-0.13(.21)$ & $0.20^{\mathrm{a}}(<.01)$ & $-0.26^{\mathrm{a}}(<.001)$ \\
\hline$\Delta$ Bone width & $0.43^{\mathrm{a}}(<.001)$ & $-0.24^{\mathrm{a}}(.02)$ & $0.56^{\mathrm{a}}(<.001)$ & $-0.31^{a}(<.01)$ & $0.47^{\mathrm{a}}(<.001)$ & $-0.35^{\mathrm{a}}(<.001)$ \\
\hline$\Delta$ Medial mucosa width & $-0.03(.76)$ & $-0.21^{\mathrm{a}}(.04)$ & $-0.08(.43)$ & $-0.03(.79)$ & $-0.07(.35)$ & $-0.16^{\mathrm{a}}(.03)$ \\
\hline
\end{tabular}

a Pearson correlation coefficients that were significant at the $P<.05$ level.

\begin{tabular}{lcc}
$\begin{array}{l}\text { Table 3: Multiple linear regression models predicting side-to-side } \\
\text { inferior turbinate measurement differences }\end{array}$ \\
\hline $\begin{array}{c}\text { Dependent } \\
\text { Variable/Predictor }\end{array}$ & $\begin{array}{c}\boldsymbol{\beta} \text { Coefficient } \\
\text { (Standard Error) }\end{array}$ & $\boldsymbol{P}$ Value \\
\hline$\Delta$ Lateral offset & & $<.001^{\mathrm{a}}$ \\
NSD height & $-0.10(0.02)$ & $<.001$ \\
NSD severity & $0.36(0.07)$ & $<.001$ \\
$\Delta$ Width & & $<.001^{\mathrm{a}}$ \\
NSD height & $-0.12(0.03)$ & $<.001$ \\
NSD severity & $0.28(0.08)$ & $<.001$ \\
$\Delta$ Bone width & & $<.001^{\mathrm{a}}$ \\
NSD height & $-0.06(0.01)$ & $<.001$ \\
NSD severity & $0.22(0.02)$ & $<.001$ \\
$\Delta$ Medial mucosa width & & $.06^{\mathrm{a}}$ \\
NSD height & $-0.05(0.02)$ & .03 \\
NSD severity & $-0.04(0.06)$ & .45 \\
\hline
\end{tabular}

a Overall model $P$ value.

Regression models were constructed with $\Delta$ lateral offset, $\Delta$ width, $\Delta$ bone width, and $\Delta$ medial mucosa width as the dependent variables, respectively, while NSD severity, NSD height, $\mathrm{CB}+$, and appropriate statistical interaction terms were the independent variables. No statistically significant interactions were identified, so these terms were removed. Because $\mathrm{CB}+$ was highly associated with NSD height $(P<.001)$, these variables essentially conveyed the same information so that both could not achieve significance within the same model. Because the models containing NSD height and NSD severity had the best overall statistical significance, $\mathrm{CB}+$ was removed from the regression models. The regression models for $\Delta$ lateral offset, $\Delta$ width, and $\Delta$ bone width reached significance $(P<.001)$, with all of these variables showing an inverse relationship with NSD height and a positive relationship with NSD severity (Table 3 ). The model for $\Delta$ medial mucosa width approached, but did not reach, statistical significance $(P=.06)$. In other words, as the nasal septum further deviates, the inferior turbinate on the concave side of the septum becomes asymmetrically enlarged, but the degree of enlargement is abated as the apex of the NSD moves farther away from the floor of the nasal cavity. This relative increase in inferior turbinate size can be explained with this model as greater projection of the turbinate bone more medially into the nasal cavity ( $\Delta$ lateral offset) and an increase in the width of the pendulous portion of the inferior turbinate ( $\Delta$ width), with the latter driven by thickening of bone more than mucosa.

Middle turbinate mucosal thickness did not differ significantly between the concave (mean, $2.2 \pm 0.7 \mathrm{~mm}$ ) and convex (mean, $2.2 \pm 0.6 \mathrm{~mm})$ sides of the deviated nasal septum $(P=.99$, paired $t$ test).

\section{DISCUSSION}

Concordant with previous reports, the current study supports the association between NSD and contralateral ITH. ${ }^{2,3,7-14}$ NSD severity and NSD height best predicted the severity of ITH without significant contribution from the presence or absence of the concha bullosa. Although some of the prior reports did not objectively measure the severity of NSD, 1 study found that inferior turbinate bone thickness on the side opposite the NSD positively correlated with NSD severity as measured by septal angle and volume. ${ }^{13}$ In contrast, Akoğlu et $\mathrm{al}^{9}$ attempted to associate the angle of the deviated septum with the cross-sectional areas for hypertrophied inferior turbinate bone, mucosa, and overall size, but no significant correlation was found. This may be because a septal angle eliminates some useful information. When one measures the angle from the region of the crista galli, severe NSD centered closer to the floor of the nasal cavity and a milder NSD positioned more superiorly can yield the same septal angle but have a different impact on septal morphology and surrounding structures. Therefore, NSD in the current study was characterized by 2 variables, NSD severity and NSD height.

The elimination of the concha bullosa from the regression model does not mean that it is irrelevant, because the bivariate analysis clearly showed significant associations between the concha bullosa and the indicators of ITH (ie, side-to-side measurement differences in inferior turbinate bone width, overall width, and the degree of intranasal projection). Instead, it merely indicates that the presence of a concha bullosa did not provide additional statistical significance in a multiple regression model because it presumably conveys much of the same information as the parameters of NSD. On the basis of the current results, the severity of ITH correlates directly with NSD severity and inversely with NSD height. This correlation effectively accounts for the observation that the apex of maximal NSD tends to be located more superiorly in the presence of a unilateral concha bullosa.

Prior studies have documented the presence of ITH in NSD in a variety of different ways. Some of the earliest work on ITH used acoustic rhinometry to indirectly evaluate the extent of ITH by estimating the cross-sectional area of the nasal cavity as a function of the distance from the nostrils. ${ }^{2,7}$ Because of an incomplete response following topical nasal decongestant application, it was concluded that ITH must result from combined mucosal and skeletal hypertrophy. CT has been used as an alternative form of in vivo assessment for ITH associated with NSD by acquiring different measurements of bone and soft-tissue components of the inferior turbinate and comparing these results internally with the contralateral side or exter- 
nally with a control population..$^{8,9,11-13}$ In general, these CT data support the findings of acoustic rhinometry that compensatory ITH arises from increased bone and mucosal thickness. Additionally, as measured by distance or angle, the inferior turbinate on the concave side of a deviated septum projects farther medially into the nasal cavity. ${ }^{11,14}$ Histopathologically, Berger et $\mathrm{al}^{3}$ compared resected inferior turbinate specimens in patients undergoing surgery for NSD with ITH and compared them with freshly harvested postmortem specimens. The conchal bone in the ITH group showed a 2 -fold increase in thickness, which accounted for approximately $75 \%$ of the difference in overall turbinate thickness compared with the cadaveric controls, with no significant difference in bone type (lamellar versus compact). The mucosal contribution to ITH was much less, though the appropriateness of comparing surgically resected turbinates with postmortem specimens has been questioned. ${ }^{5}$ When viewed in aggregate, this previously published work supports compensatory ITH arising from both bone and mucosal thickening. The tendency of the bone findings to be slightly more reproducible across studies may relate to the inherent variability in mucosal thickening introduced by normal mucosal cycling. In the current study, the lack of a difference in middle turbinate mucosal thickness along the concave and convex sides of the deviated nasal septum argues against the presence of a systematic bias from the nasal cycle. However, the multivariable model for $\Delta$ medial mucosal width showed that there was no statistically significant difference $(P=.06)$, and this might be attributable to the added variability introduced by the nasal cycle. In contrast, the 3 ITH variables that included osseous structures were all highly significant.

The choice of representative measurements in the current study was grounded in the previously published body of

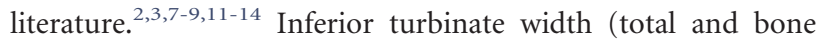
only) and the distance that the inferior turbinate projects into the nasal cavity were selected as appropriate representations of ITH. Because the medial mucosal layer of the inferior turbinate tends to be the widest because it contains the thickest lamina propria, it was also chosen for measurement. ${ }^{3}$ We chose the coronal image used for assessment through the level of the maxillary sinus ostium to include the concha bullosa, while noting that the contributions of bone and mucosa to ITH have been validated for the middle third of the inferior turbinate. , $^{8,12}$

The precise mechanism underlying the development of compensatory ITH in NSD remains unclear, but there is evidence to suggest a long-standing acquired process. Aslan et $\mathrm{al}^{12}$ stratified adult (mean age, $40.2 \pm 12.4$ years) and pediatric (mean age, $10.9 \pm 3.8$ years) cohorts into those who had NSD versus those with a straight or nearly straight septum and calculated interturbinate ratios to determine relative size differences in bone and soft-tissue components of the inferior turbinates (ie, an increased ratio suggested ITH). For bone more than soft-tissue structures, the adults with NSD had significantly higher interturbinate ratios compared with the adults with a straight septum, thereby indicating ITH. In contrast, the interturbinate ratios did not significantly differ between the pediatric groups on the basis of the presence of NSD, and the adults with NSD had significantly higher interturbinate ratios than the children with NSD. The results were inter- preted as ITH being an acquired compensatory process in NSD rather than a congenital abnormality.

A separate study compared patients with NSD and stratified them as to whether the NSD was thought posttraumatic or congenital. ${ }^{14}$ Inferior turbinate measurements were compared between the convex and concave sides of the septum to delineate ITH. In the congenital group, the bone of the inferior turbinates on the concave side of the septum projected more medially into the nasal cavity on the basis of the distance and angle relative to the lateral nasal wall. The authors concluded that the conchal bone plays a much greater role in ITH in congenital NSD, underscoring the much longer time needed to acquire osseous-versussoft-tissue changes. The notion that the mucosal component of compensatory ITH is more dynamic is also supported by a study that evaluated patients who underwent septoplasty without a turbinate operation and then underwent repeat CT at least 1 year postoperatively. ${ }^{10}$ On average, the medial mucosa of the hypertrophied inferior turbinate on the concave side of the septum preoperatively became thinner by approximately $1 \mathrm{~mm}$ after the septal deformity was corrected. This finding was presumed to represent the mucosal response to narrowing of the adjacent air channel caused by moving the septum back to midline. In contrast, the turbinate skeletal structure was unchanged.

While long-standing NSD appears to lead to the development of ITH, the precise relationship between NSD and concha bullosa continues to be debated. A significant body of evidence not only associates NSD and concha bullosa but also indicates that the NSD is typically directed away from the concha bullosa when unilateral or the dominant concha bullosa when bilateral. ${ }^{16,23,24,28,29}$ The severity of NSD tends to be greater in larger or more extensively pneumatized conchae bullosa; conversely, the prevalence of a concha bullosa correlates positively with the severity of NSD. ${ }^{23,24,28,29}$ The current results further strengthen the intimate relationship between concha bullosa and NSD by demonstrating that the apex of maximum NSD is positioned more superiorly when a unilateral concha bullosa is present and that the severity of NSD increases in direct proportion to concha bullosa width. However, causation remains uncertain. Because a number of studies have documented a preserved air channel between the medial aspect of the concha bullosa and the nasal septum, it is unlikely that an enlarging concha bullosa directly pushes the septum. ${ }^{16,23,24}$

It has been previously suggested that concha bullosa and NSD represent 2 incidental and potentially unrelated developmental anomalies that tend to appear concomitantly or that a concha bullosa develops to fill in vacant space created by a preexisting NSD, termed the "e vacuo" hypothesis. ${ }^{31}$ However, a study comparing dizygotic and monozygotic twins found that the intrapair similarities were virtually identical for the presence of a deviated nasal septum (23\% versus 25\%), but monozygotic twins had an intrapair similarity for concha bullosa of $70 \%$ compared with $25 \%$ for dizygotic twins, suggesting a genetic influence in the presence of a concha bullosa. ${ }^{32}$ Thus, a high probability of congenital coexistence of NSD and concha bullosa seems questionable. In addition, the concha bullosa would be more apt to precede NSD because of a stronger genetic link, thereby contradicting the e vacuo hypothesis. 
Additional observations have further disputed these prevailing hypotheses. ${ }^{23}$ Not all individuals with septal deviation have concha bullosa, while most cases with a large or dominant concha bullosa have septal deviation. Moreover, there are instances of medium-to-large bilateral conchae bullosa in the setting of a straight nasal septum. Consequently, it is difficult to establish a purely congenital association between the 2 anatomic variants, and the compensatory growth of a concha bullosa to fill in the space vacated by a deviated nasal septum also seems implausible. In fact, Sazgar et $\mathrm{al}^{23}$ recently hypothesized that it is the NSD that is more likely to be compensatory for a concha bullosa by synthesizing this idea with the prevailing literature and substantiating it with a discussion of fluid dynamics.

The limitations of the current study are primarily related to the generalizability of the results regarding the relationship of NSD, concha bullosa, and ITH. In an attempt to eliminate confounding variables, the strict inclusion criteria eliminated patients with active inflammatory sinus disease, posttraumatic sinonasal deformity, bilateral conchae bullosa, and small lamellar conchae bullosa. Moreover, the study population consisted of patients with a clear unilateral pattern of septal deflection, and it has been recognized that different patterns of concomitant turbinal hyperplasia and concha bullosa vary on the basis of NSD morphology. ${ }^{33}$ Last, ITH and NSD were exclusively defined by CT appearance with no correlate as to the presence of clinically significant nasal obstruction. Because the study population was limited to subjects with clear sinuses on CT, the overwhelming majority never underwent a thorough rhinologic evaluation, thereby limiting the ability to make meaningful imaging-clinical correlations. In reality, symptomatic nasal obstruction from ITH and NSD is best determined clinically. The CT-based measurements performed in this study were a tool to identify anatomic features that contribute to the development of ITH, not a recommended form of clinical assessment.

\section{CONCLUSIONS}

The degree of compensatory ITH increases in proportion to the severity of NSD and decreases as the NSD apex moves farther superiorly from the nasal floor. Although the presence of a unilateral middle turbinate concha bullosa is associated with less severe ITH, this effect is primarily attributed to the higher apex of the NSD seen with concha bullosa, as opposed to an independent relationship between concha bullosa and ITH, both of which are commonly found along the concave side of a deviated septum.

\section{REFERENCES}

1. Jackson LE, Koch RJ. Controversies in the management of inferior turbinate hypertrophy: a comprehensive review. Plast Reconstr Surg 1999;103:300-12 CrossRef Medline

2. Hilberg O, Grymer LF, Pedersen OF, et al. Turbinate hypertrophy: evaluation of the nasal cavity by acoustic rhinometry. Arch Otolaryngol Head Neck Surg 1990;116:283-89 CrossRef Medline

3. Berger G, Hammel I, Berger R, et al. Histopathology of the inferior turbinate with compensatory hypertrophy in patients with deviated nasal septum. Laryngoscope 2000;110:2100-05 CrossRef Medline

4. Berger G, Gass S, Ophir D. The histopathology of the hypertrophic inferior turbinate. Arch Otolaryngol Head Neck Surg 2006;132: 588-94 CrossRef Medline

5. Eccles R. Query, concerning mechanism of inferior turbinate enlargement. Arch Otolaryngol Head Neck Surg 2007;133:624; author reply $624-25$ Medline

6. Balbach L, Trinkel V, Guldner C, et al. Radiological examinations of the anatomy of the inferior turbinate using digital volume tomography (DVT). Rhinology 2011;49:248-52 CrossRef Medline

7. Grymer LF, Illum P, Hilberg O. Septoplasty and compensatory inferior turbinate hypertrophy: a randomized study evaluated by acoustic rhinometry. J Laryngol Otol 1993;107:413-17 CrossRef Medline

8. Egeli E, Demirci L, Yazýcý B, et al. Evaluation of the inferior turbinate in patients with deviated nasal septum by using computed tomography. Laryngoscope 2004;114:113-17 CrossRef Medline

9. Akoğlu E, Karazincir S, Balci A, et al. Evaluation of the turbinate hypertrophy by computed tomography in patients with deviated nasal septum. Otolaryngol Head Neck Surg 2007;136:380-84 CrossRef Medline

10. Kim DH, Park HY, Kim HS, et al. Effect of septoplasty on inferior turbinate hypertrophy. Arch Otolaryngol Head Neck Surg 2008;134: 419-23 CrossRef Medline

11. Jun $\mathrm{BC}, \mathrm{Kim} \mathrm{SW}$, Cho JH, et al. Is turbinate surgery necessary when performing a septoplasty? Eur Arch Otorhinolaryngol 2009;266: 975-80 CrossRef Medline

12. Aslan G, Uzun L, Ugur MB, et al. Unilateral inferior turbinate bone hypertrophy: is it compensatory or congenital? Am J Rhinol Allergy 2013;27:255-59 CrossRef Medline

13. Orhan I, Aydin S, Ormeci T, et al. A radiological analysis of inferior turbinate in patients with deviated nasal septum by using computed tomography. Am J Rhinol Allergy 2014;28:e68-72 CrossRef Medline

14. Korkut AY, Islim F, Gulseven Ciftci S, et al. Evaluation of inferior turbinate hypertrophy in patients with congenital and traumatic nasal septum deviation. J Laryngol Otol 2012;126:784-88 CrossRef Medline

15. Bolger WE, Butzin CA, Parsons DS. Paranasal sinus bony anatomic variations and mucosal abnormalities: $\mathrm{CT}$ analysis for endoscopic sinus surgery. Laryngoscope 1991;101:56-64 Medline

16. Bhandary SK, Kamath PS. Study of relationship of concha bullosa to nasal septal deviation and sinusitis. Indian J Otolaryngol Head Neck Surg 2009;61:227-29 CrossRef Medline

17. Javadrashid R, Naderpour M, Asghari S, et al. Concha bullosa, nasal septal deviation and paranasal sinusitis; a computed tomographic evaluation. $B$-ENT 2014;10:291-98 Medline

18. Kayalioglu G, Oyar O, Govsa F. Nasal cavity and paranasal sinus bony variations: a computed tomographic study. Rhinology 2000;38: 108-13 Medline

19. Lam WW, Liang EY, Woo JK, et al. The etiological role of concha bullosa in chronic sinusitis. Eur Radiol 1996;6:550-52 CrossRef Medline

20. Nadas S, Duvoisin B, Landry M, et al. Concha bullosa: frequency and appearances on CT and correlations with sinus disease in 308 patients with chronic sinusitis. Neuroradiology 1995;37:234-37 CrossRef Medline

21. Nouraei SA, Elisay AR, Dimarco A, et al. Variations in paranasal sinus anatomy: implications for the pathophysiology of chronic rhinosinusitis and safety of endoscopic sinus surgery. J Otolaryngol Head Neck Surg 2009;38:32-37 Medline

22. Ozcan KM, Selcuk A, Ozcan I, et al. Anatomical variations of nasal turbinates. J Craniofac Surg 2008;19:1678-82 CrossRef Medline

23. Sazgar AA, Massah J, Sadeghi M, et al. The incidence of concha bullosa and the correlation with nasal septal deviation. B-ENT 2008;4: 87-91 Medline

24. Stallman JS, Lobo JN, Som PM. The incidence of concha bullosa and its relationship to nasal septal deviation and paranasal sinus disease. AJNR Am J Neuroradiol 2004;25:1613-18 Medline 
25. Unlü HH, Akyar S, Caylan R, et al. Concha bullosa. J Otolaryngol 1994;23:23-27 Medline

26. Uygur K, Tüz M, Dogru H. The correlation between septal deviation and concha bullosa. Otolaryngol Head Neck Surg 2003;129:33-36 CrossRef Medline

27. Yiğit O, Acioğlu E, Cakir ZA, et al. Concha bullosa and septal deviation. Eur Arch Otorhinolaryngol 2010;267:1397-401 CrossRef Medline

28. Elahi MM, Frenkiel S, Fageeh N. Paraseptal structural changes and chronic sinus disease in relation to the deviated septum. JOtolaryngol 1997;26:236-40 Medline

29. Aktas D, Kalcioglu MT, Kutlu R, et al. The relationship between the concha bullosa, nasal septal deviation and sinusitis. Rhinology 2003; 41:103-06 Medline

30. Hatipoglu HG, Cetin MA, Yuksel E. Nasal septal deviation and concha bullosa coexistence: CT evaluation. B-ENT 2008;4:227-32 Medline

31. Stammberger H. Functional Endoscopic Sinus Surgery: The Messerklinger Technique. Philadelphia: B.C. Decker; 1991:156-68

32. Chaiyasate S, Baron I, Clement P. Analysis of paranasal sinus development and anatomical variations: a CT genetic study in twins. Clin Otolaryngol 2007;32:93-97 CrossRef Medline

33. Baumann I, Baumann H. A new classification of septal deviations. Rhinology 2007;45:220-23 Medline 